involved local institutions are private. In other cases (e.g., Greece) local institutions engaged in partnership with foreign institutions get leeway outside national rules (and cannot offer national degrees).

Local-foreign partnerships increasingly have a for-profit side. The financial incentive for Australian, UK, or US universities is clear, even if their institutions are juridically public. It appears that an increasing proportion of the local actors are for-profit, in conjunction with "branch" campuses of foreign universities.

In other respects, the for-profit growth is yet more astonishing. Several for-profit businesses invest in higher education. The three most prominent internationally are Laureate (formerly Sylvan), Apollo (which owns the massive University of Phoenix in the United States), and Whitney International. Clearly these companies are in it for profit and do not claim otherwise. Alongside them is a growing list of domestic investment companies. In some cases lines between ownership and investment are fuzzy. Laureate has often bought up existing private nonprofit institutions and invested, yet the institutions remain legally nonprofit, as law in countries such as Chile and Mexico proscribes for-profit higher education. However, the line between nonprofit and for-profit is notoriously unclear. Many legally nonprofit institutions are functionally for-profit, simply not distributing financial gains to stockholders. Meanwhile, even truly nonprofit institutions are becoming more commercial. For-profit growth is one of the striking global tendencies within the United States.

The great majority of private institutions (old and new) continue to be overwhelmingly financed privately, usually through tuition and fees.

Even where the basic private types of yesterday are the private types of today, changed mixes emerge. There is a relative decline of religious focus. Whereas elite private higher education is rare outside the United States, exceptions arise (perhaps Turkey's Bilkent University) alongside longer-standing Japanese and Korean cases. A much more common phenomenon is the development of "semielite" private institutions. These may evolve out of some of the serious demand-absorbing institutions. Though their elite nature may be more about clientele than academics, some do achieve distinction, often in a niche field. The niche field is usually business related. Semielite universities can be markedly entrepreneurial. They could evolve into a competitive threat to public universities of the second tier.

In terms of sheer numbers the most important private development is the clear dominance of demand-absorbing institutions. In certain countries (e.g., Brazil, Philippines) such institutions have for many decades held the majority of private enrollment, sometimes the majority of total enrollment. Now, however, the dominance in growth and enrollment numbers of these institutions spreads to more and more countries. Unsurprisingly, the proliferation, against a legacy of little regulation, has given rise to increased concern about quality assurance and to the establishment of public accrediting agencies in country after country.

\section{Graduate Education in Latin America: The Coming of Age JORGE BALÁn}

Jorge Balán is a senior researcher of the Centro de Estudios de Estado y Sociedad in Buenos Aires and a visiting professor at the Ontario Institute for Studies of Education at the University of Toronto. E-mail: j.balan@cedes.org.

research-based, academically oriented graduate program A had an early start in Latin America. In the I950s and I960s, many countries in the region established national councils for the support of scientific research and advanced training. During that period the leading public universities sought to build a niche for advanced training and research to expand and renovate the professoriate. Since the mid-Ig8os, the democratic regimes in the region have provided greater institutional legitimacy and more generous funding to improve the scale and scope of training and research. Within the public university, graduate education obtained a larger degree of academic and administrative autonomy.

Flying under the radar screen of university politics, graduate education is today perhaps the most dynamic and innovative sector of higher education. Its market is expanding and diversifying, responding to the manpower needs of higher education and other economic sectors and to the career needs of a growing number of graduates. Government plays a key role in stimulating demand through regulation, incentives schemes, and the provision of funds for research and development. This article examines academically oriented graduate programs (the $\mathrm{MA}$ and PhD degrees) in a few major countries in the region.

\section{Location, Scale, and Funding}

In I985 Brazil developed a plan to send I0,000 students abroad for advanced training. However, during the I990s the country gave priority to achieving greater domestic capacity for research and training in all areas of knowledge. Brazil is today the leader in the field of graduate education in the region, with an enrollment of over 100,000 graduate students in academic 
degree programs, 38 percent of them in doctoral programs. Scientific production, 85 percent located in university research and graduate training programs, has grown 2.5 times in the last I5 years. Mexico shows a larger volume of graduate students but with a very different mix: around I00,000 students were enrolled in master's programs in 2005 , five times more than in I990, but only I3,000 registered as doctoral students. Argentina ranks third, with almost 25,000 master's and 8,000 doctoral students. Chile, a smaller country, currently enrolls I3,000 master's and almost 3,000 doctoral students, while Colombia lags behind with less than I2,000 and I,000 students in master's and doctoral programs (until recently Colombia's graduate students largely concentrated in professional specialization programs). In all these countries, the figures correspond to accredited programs recognized by national agencies mandating standards monitored through peer review processes. Requirements vary significantly, with Brazil showing the highest standards under a sophisticated quality assurance system developed in the I970s. The five countries, with a combined population of approximately 370 million, by 2005 offered hundreds of doctoral programs, producing well over I0,, 00 doctorates a year.

In contrast to China, Korea, or India, in the I980s and I990 Latin America did not rely heavily on doctoral training overseas, instead building upon previous investments to expand the domestic supply. Today many fewer PhDs in the United States are granted to Latin American than to Asian students. In addition, Latin America tends to employ a larger number of the graduates with doctorates the region produces in higher education. Moreover, a greater proportion of Brazilians and Mexicans with PhDs earned in the United States-in contrast to Asians with US PhDs-plan to return to their home countries.

Doctoral programs are largely concentrated in public universities and almost entirely supported through public funding allocated to education and/or scientific research. Private universities, with few exceptions, lack the research infrastructure required for doctoral programs in the sciences and engineering, although a number of these institutions are highly competitive in the social sciences and the humanities-fields in which the master's degree is most common. The recurrent fiscal crises of the state and the equally recurrent governance crises of the public university in Latin America have not inhibited the growing scale and production of graduate and doctoral education, since the return to democratic regimes in the region, in spite of neoliberal economic policies. Public funding for research has grown in absolute and relative terms. Brazil today spends approximately I percent of its gross national product in research and development, up from 0.7 percent in the I990s, while Argentina and Chile spend a lower percentage but also have significantly increased public funding for R\&D during the years of rapid economic growth. Although still a minor player in world science, the relative weight of Latin America in world production has doubled in the last I5 years.
Industry plays a modest role in funding and execution of research and employs few people with doctorates. Yet, public universities with capacity for research developed technology transfer programs, and many projects of university-industry collaboration (with public-sector support) have proven to be successful.

\section{Research and Graduate Education in the Public MEgAUNIVERSITY}

Although the California three-tiered model was often in the minds of university reformers in Latin America, neither the idea of a research university nor the structure of a graduate school ever took off in the region. Yet, research and graduate training are gaining a more comfortable niche within the traditional megauniversity dominated by professional schools and professionally oriented undergraduate programs.

Flying under the radar screen of university politics, graduate education is today perhaps the most dynamic and innovative sector of higher education.

Governments have created significant incentives for universities to develop and support graduate programs. In some countries higher education institutions are required to offer a number of research-based graduate programs to gain university status and thus enhanced autonomy. Graduate degrees are mandatory for entry into the academic profession and provide salary incentives to current faculty, thus fostering demand for graduate education even in professional schools that traditionally required only a professional degree (i.e., engineering, law, medicine). Governments have negotiated loans from the World Bank and the Inter-American Development Bank to strengthen public university research and graduate programs.

Accreditation of graduate programs has become widespread since the I990s-the harbinger of broader efforts in quality assurance. Peer review plays a key role in accreditation systems and competitive research funding, strengthening the voice of the disciplinary-based academic communities in university affairs.

Reforms have often succeeded in shortening the length of undergraduate professional programs to four or five years. The expanding number of graduates has created a larger demand for professionally oriented graduate certificates and degrees offered by the same units and faculty in charge of academically oriented MA and PhD degrees. A market-driven, professionally oriented segment of graduate education provides some opportunities and fresh funding to the graduate faculty, enhancing its status within the university. Increased decentralization, administrative autonomy, and the pressure upon institutions to diversify funding have largely favored graduate programs and graduate faculty. Salaries for graduate faculty might 
be paid, or supplemented, by research agencies or special funding schemes outside of university control. Competitive research funding, largely from public agencies, became the rule. Graduate programs may charge fees, and in fact many specialization and master's programs are self-sustained. Diversity of funding at the graduate unit level brought increased autonomy vis-à-vis the central administration, with more flexible contract arrangements and workplace rules. Thus, graduate education became a safer niche for researchoriented, full-time faculty than in the past within the professionally dominated public university. The downside is that often this niche is quite isolated from the rest of university life, except for the market-driven specialization courses.

Last, but not least, the growth of graduate education is associated with increased differentiation within the professoriate in terms of academic status, career orientation, and academic values. While in the past an academically oriented professoriate consisted mostly of a small group of foreign-trained and internationally oriented scholars with a tenuous status within the public university, it has now become a major (although by no means predominant) segment of locally trained faculty, more often than not associated within graduate education.

\section{Doctoral programs are largely concentrated in pub- lic universities and almost entirely supported through public funding allocated to education and/or scientific research.}

\section{CONCLUSION}

Although research and advanced training are certainly the most internationally oriented segments of higher education in Latin America, as elsewhere, the risks of parochialism and inbreeding are not to be dismissed when academic communities are still relatively small, a sizable proportion of researchers are locally trained, and mobility is restricted by the small number of research-oriented universities that often favor their own doctoral graduates in recruiting new faculty. The reliance upon domestic publication in Spanish or Portuguese, particularly but not solely in the social sciences and the humanities, is a mixed blessing in this regard. Given the decreasing number of foreign-trained researchers in the region, a number of alternatives are actively explored by funding agencies, research universities, and the academic community to counteract the risks of development. International coauthorship has increased markedly in some countries and disciplines. Collaborative efforts in quality assurance involving international counterparts, often supported by international agencies, are numerous and productive. A number of research and advanced training collaborative efforts are run with the support of electronic media, supplementing the expensive academic exchange programs. Sandwich fellowships for doctoral students to spend time in overseas laboratories and institutes to complete their theses have become very common. Internationalization is thus a priority on the agenda, yet it has to compete with many other factors for domestic funding at a time when international donor agencies do not find compelling reasons to target their efforts on Latin American countries.

\section{New Developments in International Research Collaboration}

\section{Sachi Hatakenaka}

Sachi Hatakenaka is an independent consultant and researcher on higher education policy and management. E-mail: sachi@alum.mit.edu.

Thernational research collaboration has always helped scien1 tists to keep abreast of international science and to share expertise and resources. Today, one-fifth of the world's scientific papers are coauthored internationally-a result of increasingly easy communication and cross-border travel. However, a new character of international collaboration is emerging, as scientific research has become an integral part of economic and innovation policy and international collaboration has become a key element in globalization strategy.

\section{The Background of Such Changes}

The perception of a "knowledge economy" matured. Knowledge economy has become a key term not only in developed countries but increasingly in developing countries. Excellence in science is a prerequisite for future economic success, and international collaboration is seen as a key mechanism for international scientific competitiveness.

Some emerging economies, such as China and India, are changing the meaning of international collaboration. Today global networks are known to have contributed significantly to the success of Silicon Valley. It is possible for the old economies to benefit directly from the information technology boom in India or from high-tech electronics in China, by being connected. Moreover, the success of these countries does not derive just from cheap labor. China and India are attracting global R\&D activities-something that old economies in North America and Europe have been trying to do for decades. The old economies are keen to establish connections to these new powerhouse economies-not only in downstream industries but also in upstream science.

The world is increasingly united on the need for research and innovation to tackle global challenges such as poverty and 